\title{
Towards Worldwide Amblyopia Elimination - Vision Screening
}

\author{
a report by \\ Robert W Arnold \\ The Alaska Blind Child Discovery (ABCD) Project, Pediatric Ophthalmology and Strabismus, Ophthalmic Associates, Anchorage, Alaska
}

DOI: 10.17925/EOR.2009.02.01.91

Amblyopia can be defined as the deficient development of brain vision during the first decade of human life, and is the topic of some excellent recent reviews. ${ }^{1-3}$ It remains a common cause of vision impairment in developed countries despite the fact that it is completely preventable and treatable. In some small-scale regional efforts in developed countries, deliberate screening combined with consistent therapy has produced dramatic reductions in amblyopia prevalence and severity. ${ }^{4-6}$

\section{World Health Organization Screening Criteria}

Ten criteria have been developed by the World Health Organization (WHO) by which community health screenings can be evaluated for potential benefits and affordability: 7 is it an important health problem?; accepted treatment for recognised disease; facilities for diagnosis and treatment; suitable latent and symptomatic stage; suitable test or examination; test acceptable to population; natural history of condition understood; agreedon policy on whom to treat; cost of finding an economic and overall health balance; and case finding should be continuous. These criteria have been applied to many processes, including vision screening for amblyopia.

There have been several prominent publications and programmes that have opposed or bypassed vision screening for amblyopia. In part, this article will focus on how several major detractors of paediatric vision screening are no longer consistent with WHO screening guidelines.

\section{Evidence-based Medicine}

The concept of evidence-based medicine requires various types of research to be hierarchically ranked in order of their pertinence and reliability, from which current knowledge concerning health interventions can be evaluated, e.g. a well-controlled, randomised clinical trial would receive higher priority than case studies or population observations. Although the US Public Health Service (USPHS) has come out with a moderately strong backing for amblyopia vision screening, ${ }^{8}$ the renowned Cochrane Collaboration has not yet given vision screening a favourable endorsement. ${ }^{9}$ This echoes a controversial report of major importance by Snowdon in the UK, which failed to find studies of sufficiently high hierarchy for paediatric vision screening and therefore recommended disbanding such efforts in the UK. ${ }^{10}$

\section{Is Amblyopia an Important Health Concern?}

Rahi et al. reviewed the outcome in a cohort of 8,432 people of whom 429 had amblyopia to determine whether these amblyopic people functioned differently from their binocular counterparts. ${ }^{11}$ With respect to "educational outcomes, behavioural difficulties or social maladjustment, participation in social activities, unintended injuries (school, workplace or road traffic accidents as driver), general or mental health and mortality, paid employment, or occupation-based social class trajectories", there was not a substantial difference. This conclusion cast doubts on the value of vision screening for amblyopia. Nilsson similarly questions the merits of pre-school acuity screening based on presumed better utility of amblyopic adults $^{12}$ than that estimated by Beauchamp..$^{13}$

Disabled people are frequently inspiring. Special Olympic athletes, injured veteran wheelchair athletes and blind mountain climbers garner cheers from audiences worldwide. A disabled person with a good attitude, or with a need to survive, has a great ability to adapt, even to fail in spite of the disability. As an internist my father was once carrying out a physical examination on an ex-Marine back from the war and could not view one retina. The military excludes monocular recruits from battle. When queried, the Marine smiled and admitted he had lost his eye and had an artificial eye long before enlisting. During each of his military physical exams, he did what many paediatric patients do: peek on their acuity tests. Instead of having his untested eye patched as the American Academy of Pediatrics (AAP) recommends, ${ }^{14}$ this Marine covered his blind 'eye' with the right hand for the first eye, and when the tester glanced at his acuity chart, the soldier switched and covered the same prosthesis with his left hand. Instead of admitting his disability and being limited by it, he was appropriately proud of having served his country.

Despite residual amblyopia from late-detected bilateral hyperopic amblyopia, the risk of loss of the sound eye remains higher for amblyopic patients. ${ }^{15}$ There is substantial cost to society from residual vision loss due to amblyopia. ${ }^{16}$ Ophthalmologists do their best to help adult patients with residual vision loss due to amblyopia, but it is not the same. Safety glasses are strongly encouraged and amblyopic patients are often denied contact lenses or elective refractive surgery by conservative ophthalmologists. Amblyopic patients are considered 'one-eyed' with respect to risk-benefit discussions of cataract surgery or retinal surgery. Therefore, the concern is not whether amblyopic patients can adapt and function; vision screening addresses the matter of whether society is ready to allow children to develop or retain the residual vision impairment. The wheelchair athlete does not want her child to have a leg taken off. The blind climber does not ever want to let his child go blind. Similarly, public health policy makers should not deny amblyopia screening and treatment because some adult amblyopic patients can adapt to their disability.

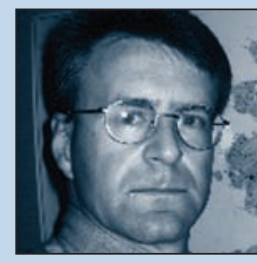

Robert Arnold is a paediatric ophthalmologist in Anchorage, Alaska. He is certified by the American Board of Ophthalmology and has surgical privileges at Providence, Alaska Regional and Alaska Native Hospitals, as well as satellite clinics in Wasilla and Kodiak. He has served as Chairman of the Vision Screening Committee for the American Association for Pediatric Ophthalmology and Strabismus (AAPOS) and is an investigator for the Pediatric Eye Disease Investigator Group (PEDIG). E: eyedoc@alaska.net 


\section{Accepted Treatment for Recognised Disease}

The previous lack of large-scale randomised studies for amblyopia have now been addressed by the National Institutes of Health (NIH)supported Pediatric Eye Disease Investigator Group (PEDIG) in a series of evolving, related Amblyopia Treatment Studies (ATS). It is now clear that amblyopia can indeed be treated, ${ }^{17}$ that refractive correction is extremely important ${ }^{18-20}$ and that patching works when the benefit of spectacles has plateaued. ${ }^{21}$

\section{Facilities for Diagnosis and Treatment}

In developed countries the diagnosis of amblyopia, or conditions leading to it, are easily performed by eye doctors with experience in dealing with small children. A 'confirmatory examination' differs from a low-risk general population comprehensive exam because the patient is a child referred for vision screening and therefore is at higher risk. The exam follows a directed history and determines age-appropriate acuity, with monocularity assured by patching the non-tested eye. Pupils and peripheral fields are tested in addition to general observations of the patient, neuro-status, head, orbits and ocular adnexa and ocular media clarity. The refraction includes determination of accommodative status, ideally with dynamic retinoscopy or office photoscreening, and then cycloplegic refraction. Finally, the retina and optic nerve are examined.

Treatment is primarily office- and home-based with spectacles and/or contact lenses prescribed and fitted. Patching and/or atropine penalisation are carried out at home. Outpatient surgery may be required for ocular media opacity, eyelid obscuration of vision or strabismus. However, in developing countries facilities are scarce and intermittent screening, remote exams and spectacle delivery are usually possible on a charitable basis only. ${ }^{22}$ Crude occlusion patches can be constructed from adhesive tape. Patients reluctant to comply with occlusion may be offered sutured occluder treatment to afford four weeks ( 400 hours) of full-time patching and an expected 3 logMAR lines of acuity gain. ${ }^{23}$ There is strong evidence that the main benefit from patching occurs within 170 hours in a child four years of age and within 236 hours in a child six years of age. ${ }^{24,25}$ Indeed, children with a severe risk factor for congenital cataract who have good intraocular lens and initial patch therapy may even retain ${ }^{26}$ good acuity with 'early' discontinuation of intense patch therapy. ${ }^{27}$

\section{Suitable Latent and Symptomatic Stage}

There is conclusive evidence for a latent period in human amblyopia, although it does not correlate exactly to animal evidence from Hubel and Wiese $^{28}$ and von Norden. ${ }^{29}$ Early intense intervention with unilateral congenital cataract before six weeks to four months of age results in better acuity. ${ }^{30}$ Amblyopic children detected by photoscreening before two years of age had 1 logMAR line better treatment acuity than those detected between three and four years of age. ${ }^{31}$ In the PEDIG ATS Number 1, longterm follow-up in premier paediatric eye practices showed better eventual acuities in those starting at less than five years of age (20/25) versus those starting at five or six years of age (20/32).32 PEDIG also found worse responses to amblyopia treatment in older teens than in pre-teens. ${ }^{33}$ Therefore, there is an obvious latent period and advantage with respect to outcome acuity with early detection.

Amblyopia in children may not be symptomatic. Posterior congenital cataracts (rare) and anisometropia (common) are extremely occult. Constant strabismus is usually observed early by parents ${ }^{34}$ and this has excellent predictive value in amblyopia screening. ${ }^{35}$ Risk factors for most cases of amblyopia include high refractive error, constant strabismus and ocular media opacity. Although many of these may not be directly observable in pre-literate children, objective screening - i.e. the Brückner Test - photoscreening and remote autorefraction ${ }^{35}$ can detect all of these factors in young children and infants.

\section{Suitable Test or Examination}

Amblyopia is the sensory loss of potentially learned brain vision, primarily in the central visual field, and therefore is represented by diminished bestcorrected visual acuity. For this reason, paediatrician and community screening of monocular acuity has been the mainstay of amblyopia screening. Indeed, acuity screening can be a suitable tool for detection. Objective tests are designed to reveal amblyopia risk factors from passive children. Photoscreening emits flashes of light relatively coaxial to the camera lens, which allows an analysis of reflected crescents of light reflected from defocused or misaligned eyes ${ }^{36,37}$ and is related to dynamic retinoscopy. ${ }^{38}$ Remote autorefraction determines refractive error by wavefront analysis. ${ }^{39}$ Both photoscreening and remote autorefraction can detect high levels of refractive error, which are amblyopia risk factors.

An eye examination can also detect amblyopia and risk factors for amblyopia. Paediatric ophthalmologists usually perform complete examinations on infants referred with tear duct obstruction ${ }^{40}$ and therefore detect and treat amblyopia in about $5-10 \%$ of cases. When balancing the cost and benefit of overall paediatric care, the AAP does not recommend a complete eye examination unless the child is symptomatic or fails a series of age-appropriate vision screenings. ${ }^{14}$ On the other hand, organised optometry and optical dispensing industries have proposed and implemented community programmes designed to use widespread paediatric complete examinations in part to detect amblyopia and several other vision and learning-related conditions. A programme called 'InfantSEE', sponsored by Johnson \& Johnson, is designed to encourage optometrists who visit their Florida resort centre to perform checks on children six months of age. ${ }^{41}$ Another programme is called 'Check Yearly-See Clearly', which espouses annual exams for all children. ${ }^{42}$ The American Optometric Association (AOA) has promoted 'mandated prenursery eye examinations', which are now adopted as law in Kentucky, ${ }^{43}$ Missouri and Illinois. The AOA recommends that children have a complete eye examination every two years. ${ }^{44}$ It is worth remembering that these examinations are performed on low-risk populations and are therefore 'comprehensive eye exams' and not confirmatory exams. So, screenings and exams can detect amblyopia; which are suitable? This requires evaluation of validity. Matters of cost-effectiveness will be covered in a subsequent WHO guideline section.

If a group of young children after careful confirmatory examinations were sorted into a group at high risk of amblyopia or with amblyopia versus those without amblyopia, you would have 'true' and 'false' groups. Screening sorts the entire group into high risk versus low risk. A measure of how well the screening finds all of the true patients is sensitivity. Another important validation statistic is specificity, which determines how well the screening identifies the true or false. The proportion of those who screen positive who actually are true are called 'predictive value'. In a 'real-world' community screening, predictive value can be determined by performing confirmatory exams on just the small percentage referred, whereas determining sensitivity and specificity requires performing confirmatory exams on all of the children. The number of studies needed to accurately achieve this is small because such studies are expensive. ${ }^{45,46}$ The $\mathrm{NIH}$-supported Vision in 
Pre-schoolers Studies (VIPS) used a disease-enhanced population; therefore, it is a variation on an ideal validation study. ${ }^{47,48}$

It is extremely important that validation studies use identical standards or else the paediatric community will be 'comparing apples with oranges'. The American Association for Pediatric Ophthalmology and Strabismus (AAPOS) proposed and published such a list of conditions that may be found in a confirmatory exam to place a pre-school child at sufficiently high risk of developing amblyopia. ${ }^{26}$ VIPS later developed more complex groups of amblyopia risk factors, ${ }^{47}$ but unfortunately has not published its results using the AAPOS guidelines. ${ }^{49}$

A graphic representation of how sensitivity and specificity change for a given screening - by varying the referral criteria - is called the receiver-operator characteristic (ROC) curve. ${ }^{50}$ Interpretations from most screenings can be divided into 'refer', 'pass', 'unable to test' or 'inconclusive'. Screenings that have a high proportion of inconclusive/unable to test are of less value than those that provide a definitive answer for each child screened, unless it is simple for technicians and parents to repeat the screening. The Alaska Blind Child Discovery $(A B C D)$ project has defined a new set of validation statistics that incorporate inconclusive/unable to test results into the denominator, therefore favouring definite interpretations, and are particularly applicable for rural and remote screenings. $.51,52$

'Conventional vision screening' is acuity testing with various methods to assure monocularity and is, relatively speaking, the 'new kid on the block'. A number of prominent paediatric ophthalmologists assume that acuity screening is inexpensive, easy and reliable, and therefore are sceptical about objective screening that involves potentially expensive equipment. Few academic paediatric ophthalmologists have spent time 'in the trenches' performing community mass paediatric vision screening themselves. Careful development, validation and improvement of vision screening is difficult. ${ }^{46,53}$ It is much easier to scientifically demonstrate the imperfection of a new method than it is to innovate and develop. To date, the most extensively used technology has been Howard Freedman's Polaroid-based, sequential, orthogonal, off-axis MTI photoscreener (see Figure 1). ${ }^{54} \mathrm{It}$ is much easier for paediatric ophthalmologists to apply vision screening technology to their own enhanced-prevalence practices and determine that vision screening is not perfectly valid ${ }^{55-58}$ or difficult to interpret. ${ }^{56}$ Some noble developers of objective screening technology, facing a hostile business and legal climate, have also suffered relative academic humiliation, discouraging some from advancing their prototypes to better versions. ${ }^{54,59-61}$ There is clinical evidence that emerging objective technology can outperform acuity screening in terms of validity, speed, testability, screener skills and acceptability. ${ }^{62-65}$ With time, experience and encouragement, vision screening with consistent, monocularity-assured acuity testing can be performed in co-operative pre-schoolers. ${ }^{5}$ In a practical sense, mass acuity screening of children is much more feasible after nursery age, and is not feasible children with language or developmental disabilities. ${ }^{66,67}$ Therefore, it is not a question of whether objective tests or acuity tests are better: they should be used in age-related sequence during the years of amblyopia susceptibility.

A profound mistake in amblyopia screening is to focus too much on sensitivity rather than on the predictive value and its inversely related specificity. Manufacturers and paediatricians favour the most sensitive test because they are afraid of missing any low-vision children in that single test. Remember that the AAP recommends a series of tests rather than a
Figure 1: Howard Freedman and Robert Arnold Hold the Original MTI Polaroid Photoscreener Prototype

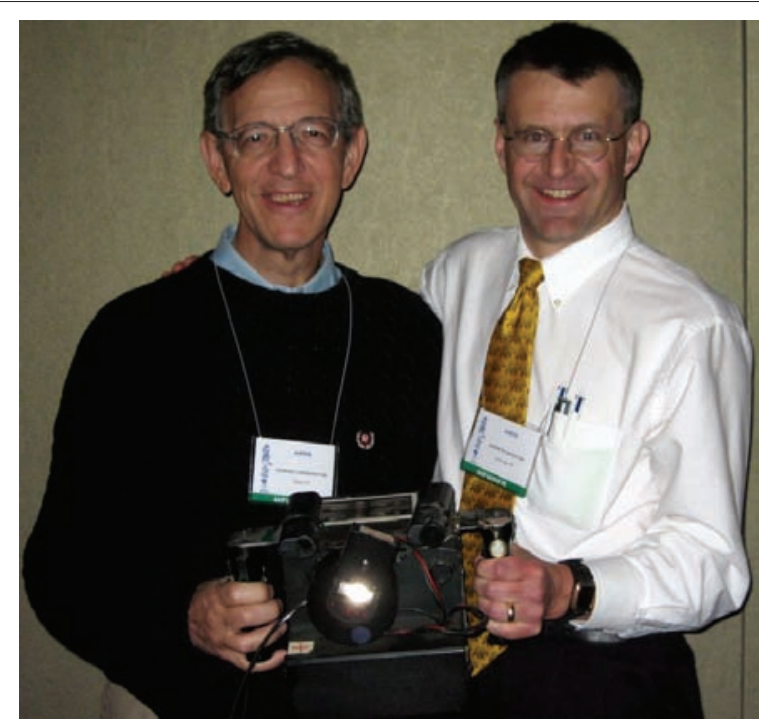

single test. Parents and busy paediatric ophthalmologists favour a test with high specificity manifest in high positive predictive value. When 10 new children are referred from a screening, it is encouraging if at least seven have real amblyopia risk. When polled, primary care doctors wanted a vision screen with predictive value over 90\%;68 few programmes have achieved this low false-positive rate. ${ }^{51}$ The ROC curve shows that when sensitivity goes up, specificity will go down, and vice versa.

The three-phase VIPS were designed under the assumption that a single pre-school screening or exam was sensitive enough to detect all cases of amblyopia. Consequently, commercially available vision-screening technology was compared with referral criteria either pre-determined (MTI and iScreen) or in-study calibrated with a relatively low specificity to yieldcompared sensitivity. ${ }^{47}$ The first phase of VIPS was performed mainly by expert paediatric optometrists, with 11 screenings, including patched acuity, performed in pre-school head-start children. Due to the potential photoreceptor wash-out of the camera flash, the photoscreeners were not randomised in order, but rather performed at number 10 and 11 (last) of all tests. Two objective tests had high sensitivity for VIPS criteria: the Welch Allyn Suresight (remote autorefractor) and the Nikon Retinomax, which touches the child's face. However, the photoscreeners (MTI with voice interpretation), iscreen and the precursor to PlusOptix failed to make the sensitivity threshold to continue into phase two of VIPS. VIPS did not include the other photoscreeners (EyeDx or Vision Research). VIPS phase one showed that the paediatric optometry exam outperformed all available screening technology with respect to sensitivity; however, paediatric optometry dynamic retinoscopy was also quite sensitive. Initially, VIPS was to have had three phases, starting with expert paediatric screening professionals and then moving through skilled nurses (phase two) and finally to lay screeners (phase three). Unfortunately, the validity of the technology surviving VIPS phase one faltered in phase two, with referral criteria for patched Lea acuity moved to five feet from 10 feet and referral criteria Welch Allyn Suresight further calibrated by study, with the result that VIPS three was never funded. One false conclusion made from phase one of VIPS was that comprehensive community optometry exams were better than any available screening technology; this has been used to promote mandated pre-nursery exams. Community comprehensive non-cycloplegic eye exams are not the confirmatory paediatric subspecialty exams of VIPS. 
Figure 2: US Vice Presidential Candidate Sarah Palin Photoscreens Her Daughter Willow with the PlusOptix S04

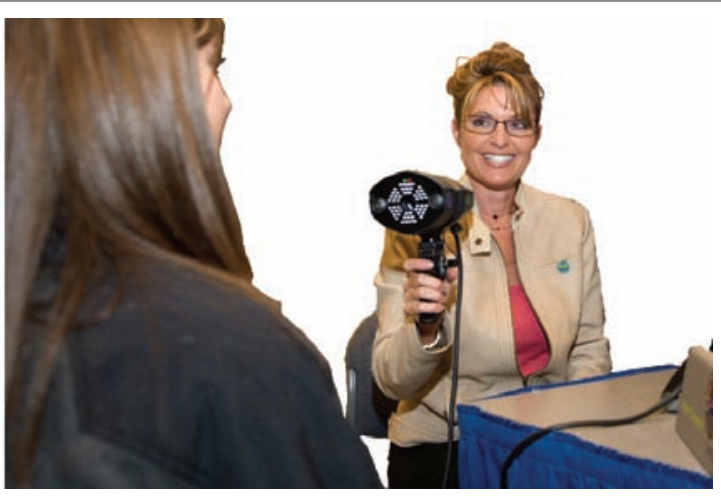

Willow's amblyopia was detected by Lions Club photoscreening at the Alaska State Fair, leading to her successful recovery from amblyopia through a Pediatric Eye Disease Investigator Group amblyopia randomised trial.

Are the available screening tests suitable for screening all pre-schoolers regardless of age? Do they work in infants, toddlers and nursery-age children? The testability rates of the VIPS-favoured Nikon Retinomax falls off under four years of age. ${ }^{64}$ The Welch Allyn Suresight can have reasonable testability down to less than three years of age, but has reduced predictive value. ${ }^{69}$ Remote objective tests such as Brückner or MTI photoscreening have similarly high testability and predictive value down to one year of age. ${ }^{35}$ From a practical standpoint, in prominent paediatric practices photoscreening outperforms acuity testing in pre-schoolers. ${ }^{62} \mathrm{~A}$ less dramatic advantage of photoscreening over acuity testing has been observed in school-based screening of younger students. ${ }^{66}$ Acuity testing with monocularity requires a high level of expertise of screeners, but can be a suitable screening tool for children as young as four years of age. ${ }^{5}$

The prevalence of amblyopia varies between communities, but it is probably between 2 and $4 \% .{ }^{45}$ Strabismus occurs in about $2.5 \%$ of children, with the frequency increasing after three years of age. An overlapping $2 \%$ have amblyopia, of whom $80 \%$ have abnormal refractive error that can be detected by objective screening. Experienced, widespread charitable photoscreening has a referral rate of $5-6 \%$ with a predictive value of $75-85 \%$, indicating that Alaska has at least a $5 \%$ AAPOS guideline condition prevalence, whereas Tennessee has about 3.5\%. We hope the Multi-Ethnic Pediatric Eye Disease Study (MEPEDS) group will publish the prevalence of AAPOS-guideline gold standard conditions. ${ }^{26}$ If the prevalence of conditions such as strabismus and amblyopia in a defined population cohort are known, reliable estimations of validity to future technology will be much easier and cheaper than with the VIPS study. ${ }^{70}$

If paediatric vision-screening methods are applied to children who do not have obvious strabismus, developmental delay or syndromes or strong family histories, no-one knows whether or not they have amblyopia until a confirmatory exam is performed. Amblyopia risk factors are known to evolve in some children. As long as a series of age-appropriate screenings is applied, initial screening with high predictive value will be best, followed by more sensitive tests at later ages. Two long-standing, state-wide specific photoscreening studies emphasised the specificity of age-related tests instead of setting referral criteria that were too sensitive; neither has had adverse eventual sequelae from presumed false-negative results..$^{71}$ Other objective programmes can achieve similar success. ${ }^{72}$ For these reasons, specific photoscreening during pre-school and nursery entry followed by sensitive, patched, surround/crowded logMAR acuity is favoured by the $A B C D$ project. 52

\section{Is the Test Acceptable to the Population?}

This depends on cost, availability, scheduling and whether or not it is child-friendly. Vision screening is not painful unless the occlusive acuity no-peeking patch has a strong adhesive. Vision screening does not require removal of clothing and is non-invasive. The flash of some photoscreeners will make young children upset, but not as much as the close remote autorefractors, i.e. Nikon Retinomax. On the other hand, treatment requires glasses that many people consider socially unacceptable or not durable. Neither patching nor atropine penalisation is easy, although the former is less preferred for many families. ${ }^{73}$ School attendance is more difficult with atropine therapy even though compliance may be better. Surgery scares many families and may not be affordable. The current screening methods are well accepted by most families in developed and developing countries. In general, courses of amblyopia therapy are fairly well accepted. Better data on the level of intensity of therapy and the duration of therapy for a given patient would greatly enhance this. Parents and paediatricians would like to know when the amblyopia therapy is complete so that their child will not lose vision when they stop optical and preference therapy.

\section{Natural History of Condition Understood}

\section{Studies of Non-compliance}

Of the WHO screening criteria, this is the least defined area with respect to paediatric amblyopia screening. This is because there have not been many long-term, large-scale population studies that carried out confirmatory exams on several thousand infants, only to monitor them annually with those having significant amblyopia risk factors remaining untreated. The UK Avon Longitudinal Study of Parents and Children (ALSPAC) received institutional review board (IRB) approval to deliver extra versus additional levels of amblyopia screening and randomised treatment as both arms of the study provided more care than leaving children outside the study; ALSPAC found that the screened children had high levels of hyperopia. Crosssectional studies demonstrate that the proportion of children with strabismus, specifically accommodative esotropia and associated amblyopia, increases with age. ${ }^{45}$ Toddlers referred by photoscreening and receiving treatment had better acuities than children detected one or two years later. ${ }^{31}$ Studies on non-compliant amblyopic cases suggest that either they do not achieve the expected recovery of acuity ${ }^{23}$ or they regress. ${ }^{74}$

\section{Agreed-on Policy on Whom to Treat}

\section{Mandated Exams versus Defined Amblyopia and Risk}

The PEDIG studies suggest that there is a relatively wide window for starting optical and patching therapy in literate children four to seven years of age. However, waiting more than one year with a known amblyopic child, particularly one with more severe amblyopia, is not consistent with PEDIG findings. There has been concern that early correction of hyperopia may interfere with emetropisation; however, the ALSPAC study would argue against this. ${ }^{6}$ Little has been published in terms of ongoing care compared with the timing and initial dose of amblyopia therapy. ${ }^{75} \mathrm{It}$ is much less clear at what age therapy - including optical - can cease.

Lempert noted anatomical differences in the eyes and optic nerves of children with conditions others may pass off as purely anisometropic amblyopia. ${ }^{76-79}$ Other children have decreased acuity combined with partial media opacity, nystagmus, developmental delays, etc., and are rarely included in randomised studies such as PEDIG ATS. Large-scale, prospective amblyopia studies have far more reliable data on starting amblyopia therapy 
than appropriate adjustments or dosages during ongoing therapy. Any prospective study on amblyopia that requires acuity for entry limits our data on the potential merits of pre-literate, amblyopia treatment or prevention in children referred by objective screening. ${ }^{31}$ Therefore, additional constitutional and ocular conditions may modify the ideal outcome of amblyopia therapy (glasses, contact lenses, patching and/or atropine). Paediatric ophthalmologists agree on the merits of giving a robust initial effort and persisting for as long as benefits are documented.

One of the main factors in amblyopia success is therapy compliance because, apart from patient frustration with blurring or occluding the sound eye, some dislike their spectacles or contact lenses. Achieving compliance is usually a matter of discipline in the home. Some paediatric ophthalmologists consider therapy non-compliance 'child abuse' and therefore invoke assistance with state protective services. Others seek optical, ${ }^{80}$ chemical ${ }^{81}$ and surgical methods ${ }^{23}$ to improve amblyopia therapy compliance. Even for a child with socioeconomic, systemic and ocular co-morbidities, almost all paediatric ophthalmologists will offer amblyopia therapy to those younger than eight years of age, and recent PEDIG studies suggest that efforts should be addressed to children even older than that. ${ }^{33}$ The PEDIG ATS have proved the equivalence of shorter-dose patching and atropine for moderate and severe cases of strabismic, anisometropic and mixed amblyopia. In addition to showing benefit of the lesser treatment, ATS showed no adverse effects of the randomised arm, higher dose patching or atropine. As such, several initial doses of patching are considered acceptable. Atropine daily or on weekends is useful for children on sufficiently hyperopic prescriptions. ${ }^{82}$

\section{Cost of Finding an Economic and Overall Health Balance}

For screening to be affordable, there must be some benefit in terms of either productivity gained or costs avoided. Screening costs more than no screening during the latent and treatment phase. With respect to amblyopia, a child who is screened and successfully treated and has two functioning eyes rather than just one may qualify for several jobs, e.g. law enforcement, armed services or transportation. The direct employability with respect to appearance will be enhanced by stable binocularity and the ability to wear contact lenses instead of having manifest strabismus or conjunctival evidence of multiple strabismus re-operations. The bilateral patient is less likely to lose the better eye following an accident. ${ }^{15}$ There is substantial disability if one eye is injured or lost due to asymmetric disease: loss of one eye is considered $24 \%$ of a person whereas loss of both is considered the loss of $75 \%$, according to US disability determination guidelines. ${ }^{.3}$

Objective screening, despite the expense of a photographic device, may have more cost benefit than sensory testing. ${ }^{84}$ Photoscreening takes far less time than careful acuity screening, ${ }^{63,66}$ and 'time is money' in terms of staff salaries and programme interruptions. A cost-benefit study sponsored by the Vision Council of America (VCA) (optical industry group) found that comprehensive exams were more cost-effective than liver transplants. ${ }^{85}$ Further analysis of that study revealed that vision screening was far more cost-effective, measured by quality-adjusted life-years (QALY), rather than comprehensive exams. ${ }^{86}$ When vision screening costs are combined with resultant costs to provide appropriate eye care over the first decade of life, AAP vision screening enhanced by early photoscreening outperforms the use of comprehensive single or serial eye exams. ${ }^{87}$ The quality of follow-up exams after vision screen referral varies, and there can an additional cost of overprescription of spectacles in many cases of comprehensive community examinations of children's eyes. ${ }^{88}$

\section{Case Finding Should Be a Continuous Process}

Some patients followed-up with annual cycloplegic examinations and treated for amblyopia will have evolving degrees of astigmatism, hyperopia and anisometropia, suggesting that amblyopia risk factors may be evolving in the unscreened population as well. Therefore, a single effort, no matter how sensitive, will not detect and treat all cases. On a practical basis, comprehensive eye exams of low-risk, hungry, agitated pre-nursery children by a community doctor will have far less sensitivity than careful research confirmatory exams carried out by paediatric optometrists. ${ }^{47}$ The AAP guidelines recommend a series of age-appropriate objective and sensory tests, starting with newborns, incorporating history and parent-detected signs and symptoms. ${ }^{14}$ Recent research ${ }^{31,89}$ strongly suggests that previously indicated photoscreening 90 be incorporated into new AAP guidelines and appropriately reimbursed, ideally between the age of 12 and 24 months, again between 30 and 48 months and, if available, as a more valid alternative to acuity testing in nursery-entry screening. Sensitive acuity testing with monocularity assured by patching should follow ${ }^{66}$ until children mature beyond their first (amblyopia-susceptible) decade.

\section{Conclusion}

Paediatric vision screening for amblyopia, particularly using AAP guidelines, in concert with early objective screening appears to comply with WHO guidelines for health screening. A practical implementation of such screening in the US is primarily impeded by the lack of uniform reimbursement for early objective screening, combined with lazy utilisation of patched, crowded/surround logMAR acuity screening. The majority of strabismic amblyopic patients have moderately large-angle esotropia and are detected well by parents and attentive paediatricians. Eighty per cent of amblyopic patients have a significant refractive error that can be efficiently detected early by photoscreening and remote autorefraction. If the leaders in the US support and reimburse objective screening, industry will respond with technology that is far more efficient, portable and affordable than current models. As with other healthcare systems, yesterday's state-of-theart technology from developed countries soon becomes effective when donated, or discounted, for worldwide use. The 'Magic Number', current procedural terminology (CPT) code 99174, if well reimbursed and utilised, promises to have a profound impact on amblyopia vision impairment worldwide by promoting research and development in this field.

\section{Financial Disclosure}

The $A B C D$ project has received discount objective and sensory vision screening technology from several manufacturers and Dr Arnold is an investigator and protocol developer for PEDIG.
1. Simons K, Preschool vision screening: Rationale, methodology and outcome, Surv Ophthalmol, 1996;41(1):3-30.

2. Simons K, Amblyopia characterization, treatment and prophylaxis, Surv Ophthalmol, 2005;50(2):123-66.

3. Wu C, Hunter DG, Amblyopia: Diagnostic and Therapeutic Options, Am J Ophthalmol, 2006;141(1):175-84.

4. Eibschitz-Tsimhoni M, Friedman T, Naor J, et al., Early screening for amblyogenic risk factors lowers the prevalence and severity of amblyopia, J AAPOS, 2000;4(4):194-9.

5. Kvarnstrom $G$, Jakobsson $P$, Lennerstrand $G$, Screening for visual and ocular disorders in children, evaluation of the system in Sweden, Acta Paediatr, 1998;87(11):1173-9.

6. Williams C, Northstone K, Harrad RA, et al., Amblyopia treatment outcomes after screening before or at age 3 years: follow up from randomised trial, BMJ, 2002;324(7353):1549.

7. Wilson J, Junger $G$, Principles and practice of screening for disease. In: Public Health paper No. 34. Geneva: World Health Organization, 1968.

8. Calonge N, USPSTF, Screening for visual impairment in children younger than 5 years: Recommendation Statement, Ann Fam Med, 2004;2:263-266. 
9. Powell C, Porooshani H, Bohorquez MC, Richardson S, Screening for amblyopia in childhood, Cochrane Database Syst Rev, 2005(3):CD005020.

10. Snowdon S, Stewart-Brown S, Preschool vision screening: Summary of a systematic review, Oxford: University of Oxford, 1997.

11. Rahi J, Cumberland P, Peckham C, Does amblyopia affect educational, health, and social outcomes? Findings from 1958 British Cohort, BMJ, 2006;332(7545):824.

12. Nilsson J, The burden of amblyopia and strabismus: justification of treatment and screening revisited, Arch Ophthalmol, 2008; 126(1):143-5; author reply 145-6.

13. Beauchamp GR, Chronic amblyopia and strabismus in children, Arch Ophthalmol, 2007;125(6):821-2.

14. Swanson J, Eye examination in infants, children and young adults by pediatricians: AAP Policy Statement, Ophthalmology, 2003:110(4):860-65.

15. Tommila $V$, Tarkkanen $A$, Incidence of loss of vision in the healthy eye in amblyopia, Br J Ophthalmol, 1981;65(8):575-7.

16. Beauchamp $G$, Bane $M$, Stager $D$, et al., A value analysis model applied to the management of amblyopia, $\operatorname{Tr}$ Am Ophth Soc, 1999;97:349-72.

17. PEDIG, A randomized trial of atropine vs. patching for treatment of moderate amblyopia in children, Arch Ophthalmol, 2002;120(3):268-78.

18. PEDIG, Cotter SA, Edwards AR, et al., Treatment of strabismic amblyopia with refractive correction, Am J Ophthalmol, 2007; 143(6):1060-63.

19. PEDIG, Cotter SA, Edwards AR, et al., Treatment of anisometropic amblyopia in children with refractive correction, Ophthalmology, 2006;113(6):895-903.

20. PEDIG, Wallace DK, Chandler DL, et al., Treatment of Bilateral Refractive Amblyopia in Children Three to Less Than 10 Years of Age, Am J Ophthalmol, 2007;144(4):487-96.

21. PEDIG, Wallace DK, Edwards AR, et al., A randomized trial to evaluate 2 hours of daily patching for strabismic and anisometropic amblyopia in children, Ophthalmology, 2006; 113(6):904-12.

22. Arnold AW, Arnold RW, Burma Vision website, cited 16 August 2008. Available at: http://www.burmavision.com

23. Arnold RW, Armitage MD, Limstrom SA, Sutured protective occluder for severe amblyopia, Arch Ophthalmol, 2008;126(7): 891-5.

24. Stewart CE, Stephens DA, Fielder AR, Moseley MJ, Modeling dose-response in amblyopia: toward a child-specific treatment plan, Invest Ophthalmol Vis Sci, 2007;48(6):2589-94.

25. PEDIG, Repka MX, Beck RW, et al., A randomized trial of patching regimens for treatment of moderate amblyopia in children, Arch Ophthalmol, 2003;121(5):603-11.

26. Donahue S, Arnold R, Ruben JB, Preschool vision screening: What should we be detecting and how should we report it? Uniform guidelines for reporting results from studies of preschool vision screening, J AAPOS, 2003;7(5):314-16.

27. Lambert SR, Plager DA, Lynn MJ, Wilson ME, Visual outcome following the reduction or cessation of patching therapy after early unilateral cataract surgery, Arch Ophthalmol, 2008;126(8): 1071-4.

28. Hubel $D H$, Wiesel $T N$, The period of susceptibility to the physiological effects of unilateral eye closure in kittens, J Physiol, 1970;206(2):419-36.

29. von Noorden GK, Amblyopia: A multidisciplinary approach, Invest Ophthalmol Vis Sci, 1985;26:1704-16.

30. Birch EE, Stager DR, The critical period for surgical treatment of dense congenital unilateral cataract, Invest Ophthalmol Vis Sci, 1996;37(8):1532-8.

31. Kirk VG, Clausen MM, Armitage MD, Arnold RW, Preverbal photoscreening for amblyogenic factors and outcomes in amblyopia treatment: early objective screening and visual acuities, Arch Ophthalmol, 2008;125(4):489-92.

32. PEDIG, Repka MX, Kraker RT, et al., A randomized trial of atropine vs patching for treatment of moderate amblyopia: follow-up at age 10 years, Arch Ophthalmol, 2008;126(8): 1039-44.

33. PEDIG, Scheiman MM, Hertle RW, et al., Randomized trial of treatment of amblyopia in children aged 7 to 17 years, Arch Ophthalmol, 2005;123(4):437-47.

34. Rosner J, Rosner J, Parents as screeners for strabismus in their children, J Visual Impair Blindness, 1988;82:193-4.

35. Arnold RW, Stange CA, Ryan C, The compared predictive value of Bruckner, acuity and strabismus from pediatric referrals, Am
Orthopt J, 2006;56(1):15-21.

36. Bobier WR, Braddick OJ, Eccentric photorefraction: optical analysis and empirical measures, Am J Optom Physiol Opt, 1985;62(9):614-20.

37. Roe LD, Guyton DL, The light that leaks: Bruckner and the red reflex, Surv Ophthalmol, 1984;28(6):665-70

38. Guyton DL, O'Connor G, Dynamic Retinoscopy, Binocular Vision \& Eve Muscle Surgery Quarterly, 1994;9(1):15-17.

39. Lawless MA, Hodge C, Wavefront's role in corneal refractive surgery, Clin Experiment Ophthalmol, 2005;33(2):199-209.

40. Kuo A, Sinatra RB, Donahue SP, Distribution of refractive error in healthy infants, J AAPOS, 2003;7(3):174-7.

41. Fox D, AOA's InfantSEE to Address Major Public Health Concern, 2004. Available at: www.kyeyes.org/morenews.cfm? news_id $=146$

42. Kerr N, Arnold R, Vision screening for children: current trends, technology and legislative issues, Curr Opin Ophthalmol, 2004 15:454-9.

43. Kemper AR, Fant KE, Badgett JT, Preschool vision screening in primary care after a legislative mandate for diagnostic eye examinations, South Med J, 2003;96(9):859-62

44. Scheiman $M, A m o s ~ C$, Ciner $E$, et al., Pediatric Eye and Vision Examination-Reference Guide for Clinicians, St Louis, Missouri: American Optometric Association, 1994

45. MEPEDS, Prevalence of amblyopia and strabismus in African American and Hispanic children ages 6 to 72 months the multi-ethnic pediatric eye disease study, Ophthalmology, 2008;115(7): 1229-36 e1.

46. Ottar WL, Scott WE, Holgado SI, Photoscreening for amblyogenic factors, I Pediatr Ophthalmol Strabismus, 1995; 32:289-95.

47. VIPS, Comparison of preschool vision screening tests as administered by licensed eye care professionals in the vision in preschoolers study, Ophthalmology, 2004;111(4):637-50.

48. VIPS, Dobson V, Quinn G, et al., Preschool vision screening tests administered by nurse screeners compared with lay screeners in the Vision in Preschoolers Study, 10VS, 2005; 46:2639-48.

49. Arnold RW, Vision in Preschoolers Study (letter), Ophthalmol, 2004;111(12):2313.

50. Miller JM, Designing a rational screening program, Am Orthopt J, 2006;56(1):30-34

51. Arnold RW, Highly specific photoscreening at the Alaska State Fair: Valid Alaska Blind Child Discovery photoscreening and interpretation, Alaska Med, 2003;45(2):34-40.

52. Arnold RW, The Alaska Blind Child Discovery Website, cited 10 May 2008. Available at: www.abcd-vision.org

53. Donahue SP, Johnson TM, Ottar W, Scott WE, Sensitivity of photoscreening to detect high-magnitude amblyogenic factors, J AAPOS, 2002;6(2):86-91.

54. Freedman H, Preston K, Polaroid photoscreening for amblyogenic factors, An improved technology, Ophthalmol, 1992:99:1785-95.

55. Tong $P$, A road toward effective vision screening, I AAPOS, 2007;11(3):213-14

56. Tong P, Enke-Miyazaki E, Bassin R, et al., Screening for amblyopia in preverbal children with photoscreening photographs, Ophthalmol, 1998;105(5):856-63.

57. Tong PY, Bassin RE, Enke-Miyazaki E, et al., Screening for amblyopia in preverbal children with photoscreening photographs: II. Sensitivity and specificity of the MTI photoscreener, Ophthalmology, 2000;107(9):1623-9.

58. Tong PY, Macke JP, Bassin RE, et al., Screening for amblyopia in preverbal children with photoscreening photographs. III. improved grading criteria for hyperopia, Ophthalmology, 2000;107(9):1630-36.

59. Morgan K, Johnson W, Clinical evaluation of a commercial photorefractor, Arch Ophthalmol, 1987;105:1528-31.

60. Granet $D$, Hoover A, Smith A, et al., A new objective digital computerized vision screening system, JPOS, 1999;36(5):251-6

61. Kennedy $R$, Thomas $D$, Evaluation of the iscreen digital screening system for amblyogenic factors, Can I Ophthalmol, 2000;35(5):258-62.

62. Salcido AA, Bradley J, Donahue SP, Predictive value of photoscreening and traditional screening of preschool children, $J$ AAPOS, 2005;9(2):114-20.

63. Arnold RW, Stark L, Leman RE, et al., Tent photoscreening and patched acuity by school nurses: Validation of ASD-ABCD, Binoc Vis Strabismus Quart, 2008;23(3):83-94.

64. MEPEDS, Borchert M, Wang Y, Tarczy-Hornoch K, et al.,
Testability of the Retinomax Autorefractor and IOLMaster in Preschool Children The Multi-ethnic Pediatric Eye Disease Study, Ophthalmology, 2008;115(8):1422-5, 1425, e1.

65. MEPEDS, Cotter SA, Tarczy-Hornoch K, et al., Visual Acuity Testability in African-American and Hispanic Children: The Multi-Ethnic Pediatric Eye Disease Study, Am J Ophthalmol, 2007:144(5):663-7.

66. Leman R, Clausen MM, Bates J, et al., A comparison of patched HOTV visual acuity and photoscreening, I Sch Nurs, 2006;22(4): 237-43.

67. Leman RE, Armitage MD, Arnold RW, The receiver-operator curve for flip-card surround HOTV in younger school children, Am Orthopt J, 2005;55(1):128-35.

68. Kemper AR, Clark SJ, Preschool vision screening by family physicians, J Pediatr Ophthalmol Strabismus, 2007;44(1):24-7; quiz 43-4.

69. Hudson AC, Donahue SP, Preschooler vision screening: Welch Allyn Sure Sight Instrument. Poster. Sarasota, ARVO, 30 April 2005.

70. Lang DM, Arnold AW, Leman RE, Arnold RW, Validated portable pediatric vision screening in the Alaska Bush: A VIPSlike study in the Koyukon, Alaska Med, 2007;49(1):2-13.

71. Arnold RW, Donahue SP, The yield and challenges of charitable state-wide photoscreening, Binocul Vis Strabismus Q, 2006; 21(2):93-100.

72. Donahue SP, Baker JD, Scott WE, et al., Lions Clubs International Foundation Core Four Photoscreening: results from 17 programs and 400,000 preschool children, J AAPOS, 2006;10(1):44-8.

73. PEDIG, Holmes JM, Beck RW, et al., Impact of patching and atropine treatment on the child and family in the amblyopia treatment study, Arch Ophthalmol, 2003;121(11):1625-32.

74. Simons K, Preslan M, Natural history of amblyopia untreated owing to lack of compliance, $\mathrm{Br} J$ Ophthalmol, 1999;83(5):582-7.

75. PEDIG, Holmes JM, Beck RW, et al., Risk of amblyopia recurrence after cessation of treatment, J AAPOS, 2004;8(5): $420-28$.

76. Lempert $\mathrm{P}$, Optic nerve hypoplasia and small eyes in presumed amblyopia, J AAPOS, 2000;4(5):258-66.

77. Lempert $P, A x i a l$ length-disc area ratio in esotropic amblyopia, Arch Ophthalmol, 2003;121(6):821-4.

78. Lempert $P$, The axial length/disc area ratio in anisometropic hyperopic amblyopia: a hypothesis for decreased unilateral vision associated with hyperopic anisometropia, Ophthalmology, 2004;111(2):304-8.

79. Lempert $P$, Porter $L$, Dysversion of the optic disc and axial length measurements in a presumed amblyopic population, J AAPOS, 1998;2(4):207-13.

80. Eustis $H$, Chamberlain $D$, Treatment for amblyopia: results using occlusive contact lens, J Pediatr Ophthalmol Strabismus, 1996; 33:319-22.

81. Rubab S, French D, Levin AV, Glued patches for children resistant to amblyopia occlusion therapy, Arch Ophthalmol, 2008;126(1):133-4.

82. PEDIG, Repka MX, Cotter SA, et al., A randomized trial of atropine regimens for treatment of moderate amblyopia in children, Ophthalmology, 2004;111(11):2076-85.

83. Engelberg AL (ed.), Guides to the Evaluation of Permanent Impairment. Third edition. Chicago: American Medical Assoication, 1988

84. Joish V, Malone DC, Miller JM, A cost-benefit analysis of vision screening methods for preschoolers and school -age children, J AAPOS, 2003;7(4):283-90.

85. White A, Costs and Benefits of Comprehensive Eye Exams, 28 October 2004. Available at: http://www.abtassociates.com/ Page.cfm?Pagel $=12301 \& 0 W I D=2109767275 \& C S B=1$

86. Arnold RW, Donahue SP, Compared value of amblyopia detection, Binocul Vis Strabismus Q, 2006;21(2):78.

87. Arnold RW, Armitage MD, Gionet EG, et al., The cost and yield of photoscreening: Impact of photoscreening on overall pediatric ophthalmic costs, JPOS, 2005;42(2):103-11.

88. Donahue SP, How often are spectacles prescribed to "normal" preschool children?, J AAPOS, 2004;8(3):224-9.

89. Donahue SP, Relationship between anisometropia, patient age, and the development of amblyopia, Am J Ophthalmol, 2006; 142(1):132-40.

90. Swanson J, Committee on practice and ambulatory medicine Use of photoscreening for children's vision screening (AAP Policy Statement), Pediatrics, 2002;109(3):524-25. 


\section{9th EVRS Congress}

\section{September 26th - 30th, 2009}

Palmeraie Golf Palace - Marrakech

\section{Should we Follow the Trend?}




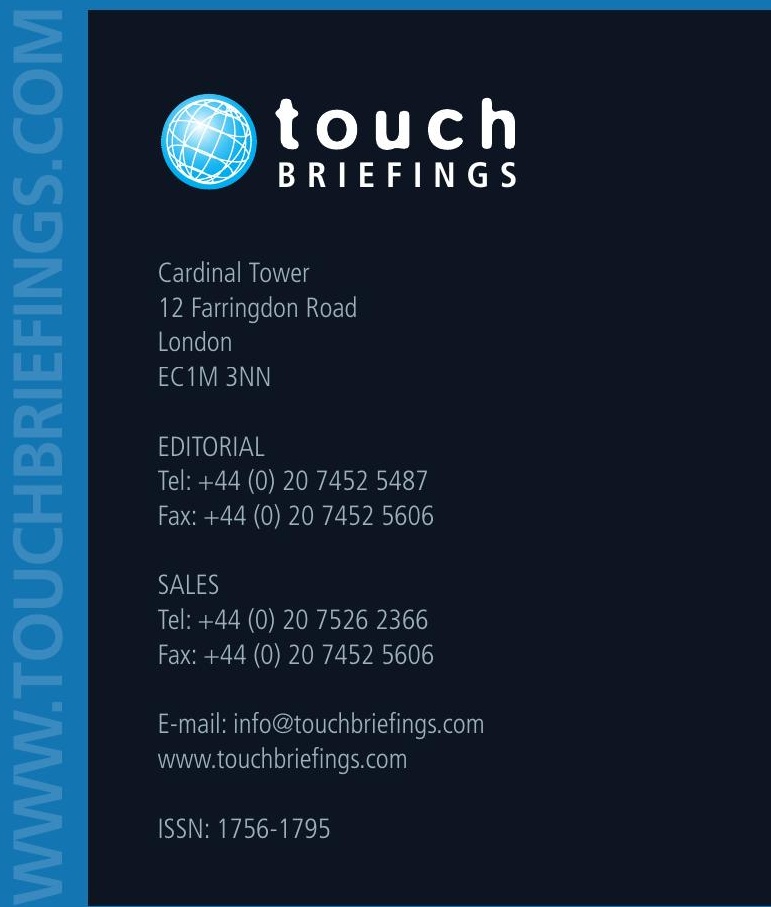

